\title{
CINNAMIC ACID AS A TEST SUBSTANCE IN THE EVALUATION OF LIVER FUNCTION ${ }^{1}$
}

\author{
BY ABRAHAM SALTZMAN AND WENDELL T. CARAWAY \\ (From the Medical and Laboratory Services of the Rhode Island Hospital, Providence, \\ Rhode Island)
}

(Submitted for publication January 6, 1953; accepted April 17, 1953)

\section{INTRODUCTION}

Previous quantitative studies of the urinary metabolites of cinnamic acid in human subjects have given promise of yielding data of clinical value in hepatic disease $(1,2)$. As is well known from both animal and human experiments, this relatively non-toxic substance is converted to and excreted as hippuric acid in the urine. The possibilities of this test material as' a model for the study of the rate of beta-oxidation by the liver of the intact subject were first suggested by Snapper (3). Snapper, Yü and Chiang demonstrated that, in the human subject, the portion of cinnamate which escaped oxidation was excreted by conjugation as cinnamoylglucuronic acid (4). Furthermore, in their subjects free cinnamic acid and cinnamoylglycine were not detected.

After oral administration of 6.9 grams of sodium cinnamate, Snapper and Saltzman showed (2) that normal subjects oxidize the main part of the cinnamate to benzoate, the remainder being conjugated as a glucuronide. In liver disease the rate of oxidation of cinnamate was decreased, and when the benzoate was produced more rapidly than it could be removed by an impaired glycine conjugation mechanism, benzoylglucuronide was formed. It was also found that by giving comparable amounts of the more insoluble and slowly absorbed cinnamic acid rather than its salt, there was a more complete oxidation of cinnamate to benzoate and less glucuronide excretion in the urine.

It would appear from the above that the preferred metabolic pathway is beta-oxidation to benzoate, with a secondary mechanism of removal as cinnamoylglucuronic acid. That the latter "defense" mechanism can be brought into greater use

1 This investigation was supported (in part) by a research grant (A-62) from the National Institute of Arthritis and Metabolic Diseases of the National Institutes of Health, Public Health Service. with impairment of oxidative function was seen in hepatic disturbances where a uniform dose of 3 grams of cinnamic acid was given to all subjects. Upon administration of the latter, a semiquantitative test for excessive excretion of glucuronides was performed on fractional urine specimens. In normal subjects there was little or no reaction with the naphthoresorcinol reagent while in hepatocellular disease almost all subjects tested showed increased excretion of glucuronides, often with a lag period. By comparison with the benzoylglucuronic acid test, greater sensitivity was noted with cinnamic acid as the test substance. The lack of sensitivity of the oral benzoic acid test has: also been noted by Sharnoff, Budnick and Jakab (5).

With the development by the authors of a method of estimation of serum cinnamic acid, a further clinical trial of cinnamic acid as a test material in the evaluation of liver function in various disease states appeared warranted. The intravenous route of administration with sodium cinnamate was chosen to overcome the marked variation in rates of intestinal absorption of cinnamic acid. It will be demonstrated that the rate of removal of cinnamate from serum, which largely is an index of hepatic oxidative ability, was closely correlated to the extent of liver injury as determined by the clinical progress of the patient and other tests.

\section{METHODS}

\section{Clinical Procedure:}

1. Oral test. Patient is fasting and receives neither medications nor i.v. glucose. A control specimen of blood is obtained. Cinnamic acid is given orally in gelatin capsules 0.6 gram per $30 \mathrm{lb}$. with water. Repeat blood specimens are taken hourly for a two hour period and an entire six hour urine sample saved for hippuric acid determination.

2. Intravenous test. Patient is fasting as above. After a control specimen is drawn, the syringe is detached and through the same needle sodium cinnamate is in- 


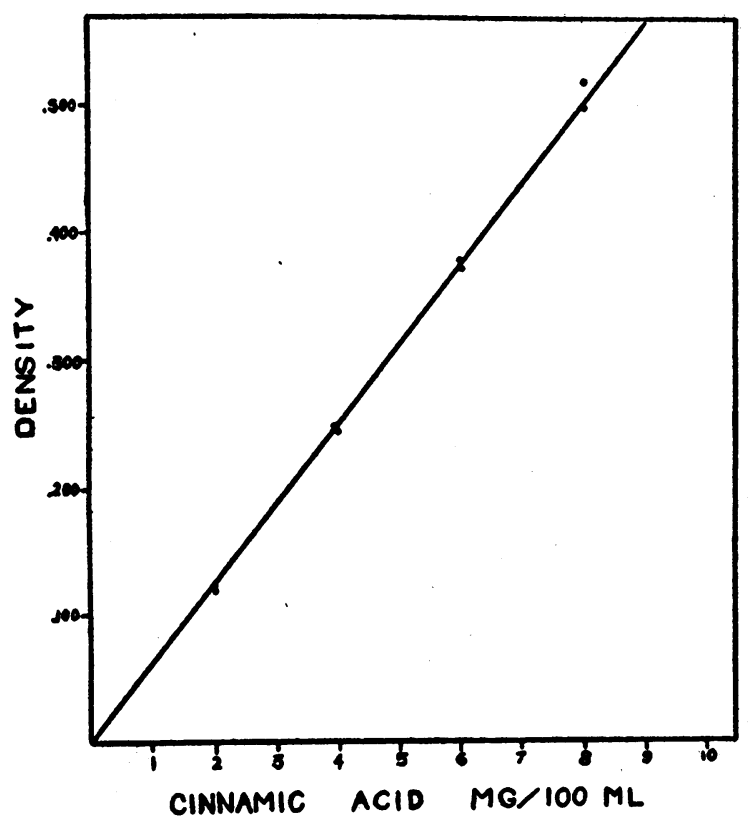

Fig. 1. Standard Curve of Cinnamic Acid

Optical density of sodium cinnamate added to serum, blank subtracted, with measurement at $270 \mathrm{~m} \mu$ in the Beckman Spectrophotometer.

jected in dosage of $5 \mathrm{mg}$. per $\mathrm{kg} .^{2}$ Repeat specimens of blood are taken at timed intervals, 5 and 20 minutes.

\section{Analytical Methods:}

Blood serum was used in all tests. Glucose was determined by the Benedict method (6) and inorganic phosphorus by the method of Benedict and Theis (7). Serum glucuronic acid was determined by a modification of the naphthoresorcinol reaction as described by Fishman, Smith, Thompson, Bonner, Kasdon, and Homburger adapted to blood serum (8). The standard curve was prepared with glucuronolactone. Readings were made at $580 \mathrm{~m} \mu$ (rather than the described $565 \mathrm{~m} \mu$ ) where the peak absorption with the Beckman apparatus was obtained. An essential element in obtaining reproducible data with this procedure is the scrupulous care given to the glassware. An important step is to leave the boiling tubes in 5 per cent $\mathrm{KOH}$ overnight. The readings obtained from sera of patients given invert sugar intravenously the previous day will be increased due to the interference of a brown color extracted by toluene.

An ultraviolet absorption procedure was devised for the estimation of cinnamic acid in serum. Sodium cin-

2 The Eli Lilly Research Laboratories, Indianapolis 6, Ind. kindly prepared a highly purified, sterile, aqueous solution of sodium cinnamate for intravenous usage. A 5 per cent solution was employed, but as that concentration is near the saturation limit, a 2.28 per cent solution was later prepared for stability. The latter is approximately isotonic, and dosage is $0.1 \mathrm{cc}$. per $10 \mathrm{lb}$. body weight. namate added to the precipitating cadmium hydroxide reagent showed a strong peak of absorption at $270 \mathrm{~m} \mu$ at which wavelengths benzoic, hippuric and phenylpropionic acids have almost no absorption. Cadmium hydroxide removes bilirubin as well as many constituents of serum absorbing in the ultraviolet without appreciable loss of cinnamic acid. Recovery experiments show that 90 to 98 per cent of the cinnamate is retained in the filtrate. A serum blank before the test is always necessary. This is a critical feature of the method, significant variations in the blank being present in some samples. Sulfonamides in particular may elevate the serum blank.

To duplicate $0.5 \mathrm{ml}$. portions of serum, add $0.5 \mathrm{ml}$. of water, $5.0 \mathrm{ml}$. of 0.58 per cent cadmium sulfate solution and $1.0 \mathrm{ml}$. of $0.1 \mathrm{~N} \mathrm{NaOH}$. Place in boiling water bath for four minutes, cool, filter. An additional $2 \mathrm{ml}$. of water is used to complete the transfer. For the reagent blank, water is used in place of serum. The filtrate is then placed in a $1 \mathrm{~cm}$. quartz cell and measured in the Beckman Spectrophotometer at $270 \mathrm{~m} \mu$. Duplicate analyses should agree within 5 per cent.

The stock standard solution is sodium cinnamate C.P., 1.15 grams per liter. It is diluted ten-fold to give concentration equivalent to 100 micrograms of cinnamic acid per $\mathrm{ml}$. The standard curve (Figure 1) is obtained by

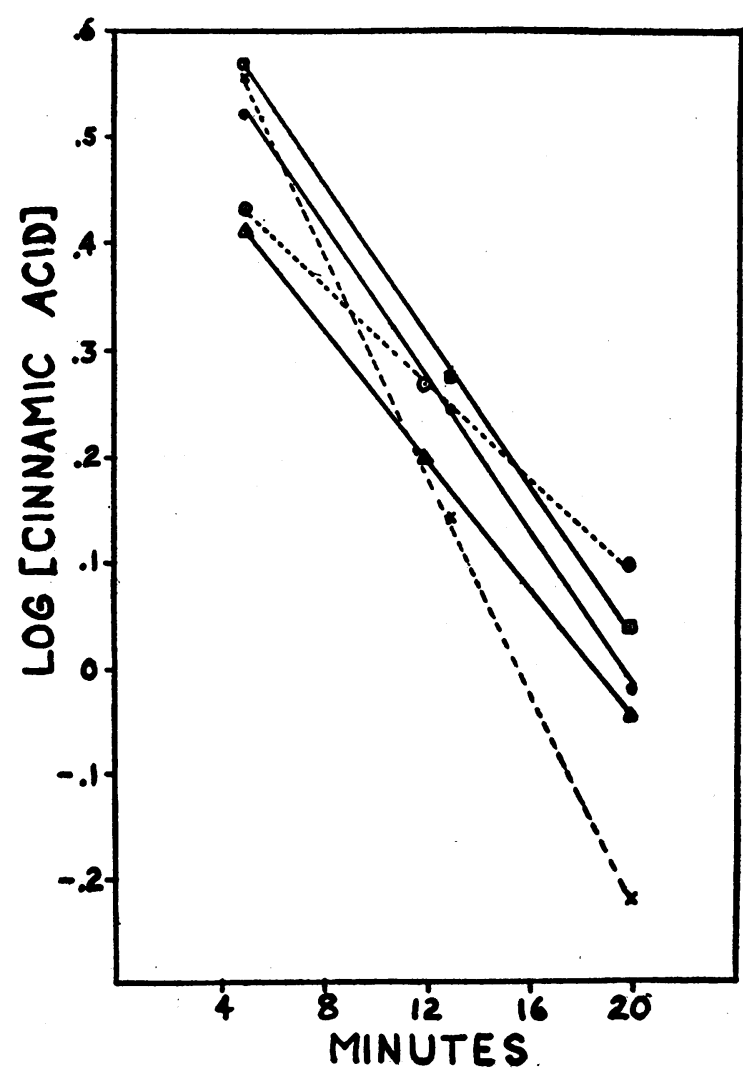

Fig. 2. Logarithmic Disappearance of Sodium CinNAMATE Following Intravenous InJection (5 MG. Par KG.) 
addition of $0.5 \mathrm{ml}$. of standard cinnamate in varying concentrations to $0.5 \mathrm{ml}$. of pooled serum and proceeding with the analysis as described above. A serum blank, containing no added cinnamate, is subtracted and the resultant optical density plotted against equivalent serum cinnamic acid. A straight line relationship is obtained, which for our Beclman Model DU Ultraviolet Spectrophotometer followed the equation:

(density unknown-density blank) $\times 15.8=\mathrm{mg}$. cinnamic acid per $100 \mathrm{ml}$. serum.

This factor (15.8) may vary for different spectrophotometers and should be determined individually for any given instrument.

To indicate the precision of the method, in a series of 100 consecutive analyses, the duplicate determinations differed by a mean of $0.10 \mathrm{mg}$. per $100 \mathrm{ml}$. serum (S.D. = 0.08 ). In addition it was thought worthwhile to determine the lowest level of cinnamic acid concentration which could be determined with accuracy by the ultraviolet technique in order to establish the significance of cinnamic acid levels reported in the lower range $(0.3$ to $2.0 \mathrm{mg}$. per $100 \mathrm{ml}$.). Recovery experiments with concentrations at intervals in this range indicated an accuracy within 0.1 mg. per $100 \mathrm{ml}$., sufficient for our purposes.

Following intravenous administration the cinnamate disappears rapidly from the blood. By measuring the concentration of serum cinnamate at intervals in five subjects, it was found that the decrease in concentration with time was logarithmic, i.e., followed a first order reaction as shown in Figure 2. The rate of decline of cinnamate level is equal to the value for the slope of the straight line and is expressed as per cent change in concentration per minute:

$$
\frac{\Delta \log C}{\Delta t} \times 100=K
$$

The hippuric acid in urine was determined by the gravimetric procedure of Quick with the addition of ammonium sulfate to decrease the solubility of the hippuric acid in the filtrate (9). Results are expressed as per cent conversion of cinnamic to hippuric acids in the six hour interval.

\section{OBSERVATIONS}

The data obtained with the oral cinnamic acid test are shown in Figure 3. The peak serum cinnamic acid level was reached in either the 1 st or 2nd hour specimen in 19 out of 20 subjects studied hourly for four hours after cinnamic acid ingestion. Because of the variation shown in the rate of intestinal absorption, the mean 1 and 2 hour level was taken for comparative purposes. In 23 normal subjects the serum cinnamic acid level was in

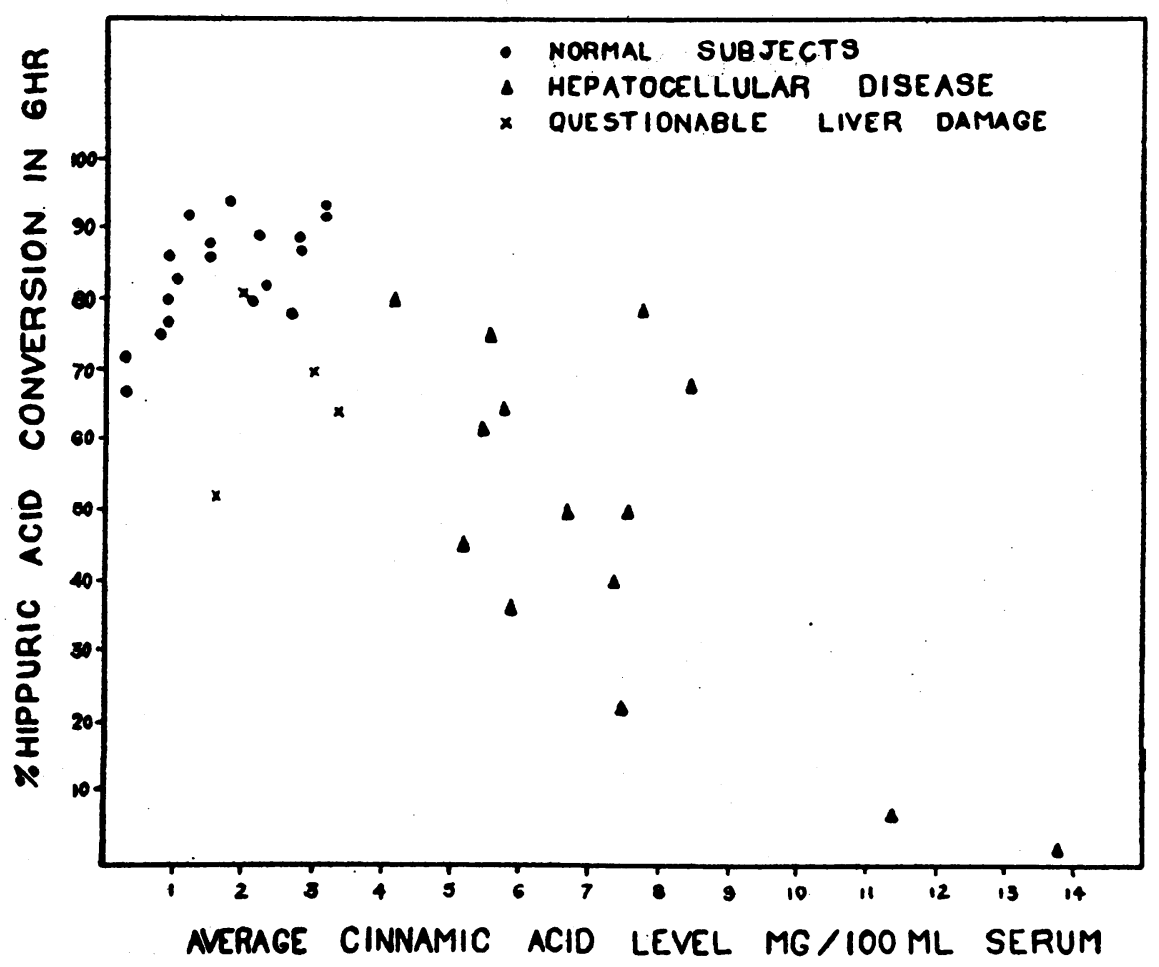

Fig. 3. Average of the 1 and 2 Hour Serum Cinnamic Acid Levels with Reiation to Per Cent Conversion of Cinnamic to Hippuric Acids in a Six Hour Preiod in Normal Subjects and Patients with Hepatocellular Disease 


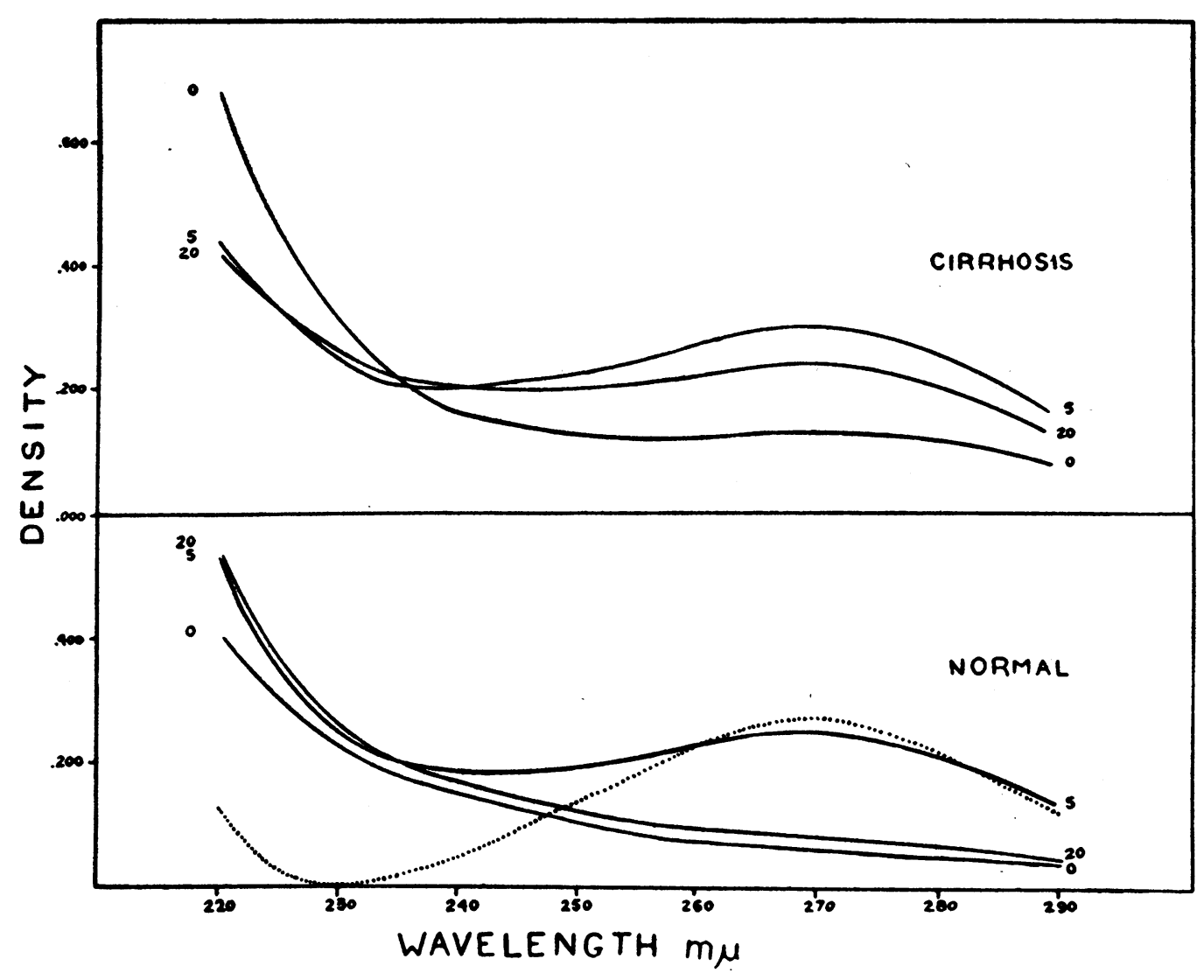

Fig. 4. Ultraviolet Absorption Curves of Serum Filtrates of a Normal Subject and a Patient with Portal Cirrhosis as Prepared with the Cadmium Hydroxide Precipitation Method of TEXT

Blood was drawn at 0,5 , and $20 \mathrm{~min}$. after intravenous injection of sodium cinnamate in dosage of $5 \mathrm{mg}$. per $\mathrm{kg}$. The absorption curve of sodium cinnamate in distilled water is indicated by the dotted line.

the range of 0.3 to $3.4 \mathrm{mg}$. per $100 \mathrm{ml}$. with absorption and conversion of cinnamic to hippuric acids of 67 to 94 per cent of the theoretical yield in the six hour period. The 17 patients with hepatocellular disease had serum cinnamic acid levels of 4.2 to $13.8 \mathrm{mg}$. per $100 \mathrm{ml}$. and showed decreased conversion to hippuric acid as a group although there was some overlap with the normal controls. There was no decided change in either the glucose, phosphorus or glucuronic acid values in any of the subjects tested. The only side effect was nausea and vomiting in one patient.

In Figure 4 the ultraviolet absorption curves of serum at 0,5 , and 20 minutes after intravenous injection of sodium cinnamate $5 \mathrm{mg}$. per $\mathrm{kg}$. are given in two typical instances. In the 5 minute specimen the normal subjects had levels of 2.7 to
$4.9 \mathrm{mg}$. per $100 \mathrm{ml}$. expressed as cinnamic acid, while in liver disturbances the 5 minute level ranged 1.9 to $5.0 \mathrm{mg}$. per $100 \mathrm{ml}$. In the normal subject the 5 minute specimen shows the cinnamate maximum at $270 \mathrm{~m}^{\mu}$ with a rapid decline to almost the control level in the next 15 minutes. The patient with liver damage, as illustrated by a patient with Laennec's cirrhosis, has a somewhat higher control level and a less marked fall of the cinnamate peak in the 20 minute specimen. Furthermore, in one-third of the cases of hepatocellular damage the observation was made that, as in this instance, both the 5 and 20 minute levels at the shorter wavelengths fall below the control level. The explanation for the latter is not known.

To date 125 intravenous sodium cinnamate tests have been performed. Side effects are a transient 
flushing in about one-fifth of the patients and in an occasional patient an epigastric cramp-like pain several minutes in duration. These reactions do not correlate to the cinnamate level attained, nor are they a constant finding with an individual patient in whom the procedure is repeated. There was no febrile response.

In Figure 5 the distribution of rates of decline of serum cinnamate in 105 tests in normals and in various pathologic conditions ${ }^{3}$ are given. The range for 18 carefully examined normal subjects, aged 14 to 64 years, was 4.0 to 6.0 per cent per minute. In the group with cirrhosis of the liver, the majority of values was between 0.8 and 3.1 per cent per minute with several higher values obtained in patients in a latent phase of their illness. Serial determinations showed a direct correlation of increased rates of cinnamate removal with improvement in the clinical status and remarkably constant rates in the unimproved patient. Weekly determinations of $\mathrm{K}$ in a patient with Laennec's

\footnotetext{
${ }^{3}$ In the 20 tests not graphed there were miscellaneous diagnoses such as Hodgkin's, leukemia and myeloma which did not fall under the listed headings.
}

cirrhosis undergoing a remission, for example, gave the following results: $1.8,2.0,2.3$, and 2.7. In hepatitis the initial values are usually low in the acute phase of the illness, rising with clinical improvement until values within the normal range are obtained. The congested liver due to heart failure may obtain a low value during the acute episode with rapid improvement as the cardiac condition is brought under control. For example, one such patient had a value of 1.6 on admission which rose to 2.8 within ten days as the heart failure subsided. The metastatic carcinoma patients, all with obvious clinical involvement of the liver, obtained intermediate values from 2.1 to 3.3 per cent per minute. All six patients with common duct obstruction were explored surgically. Diminished rates of cinnamate removal were found in the three with long-standing obstruction. Slightly diminished rates were present in the post-operative group (2.9 to 3.8 ). These were patients in the early post-operative stage where there were the factors of nutritional impairment and infection which may have had a bearing. In addition to routine liver function tests, explora-

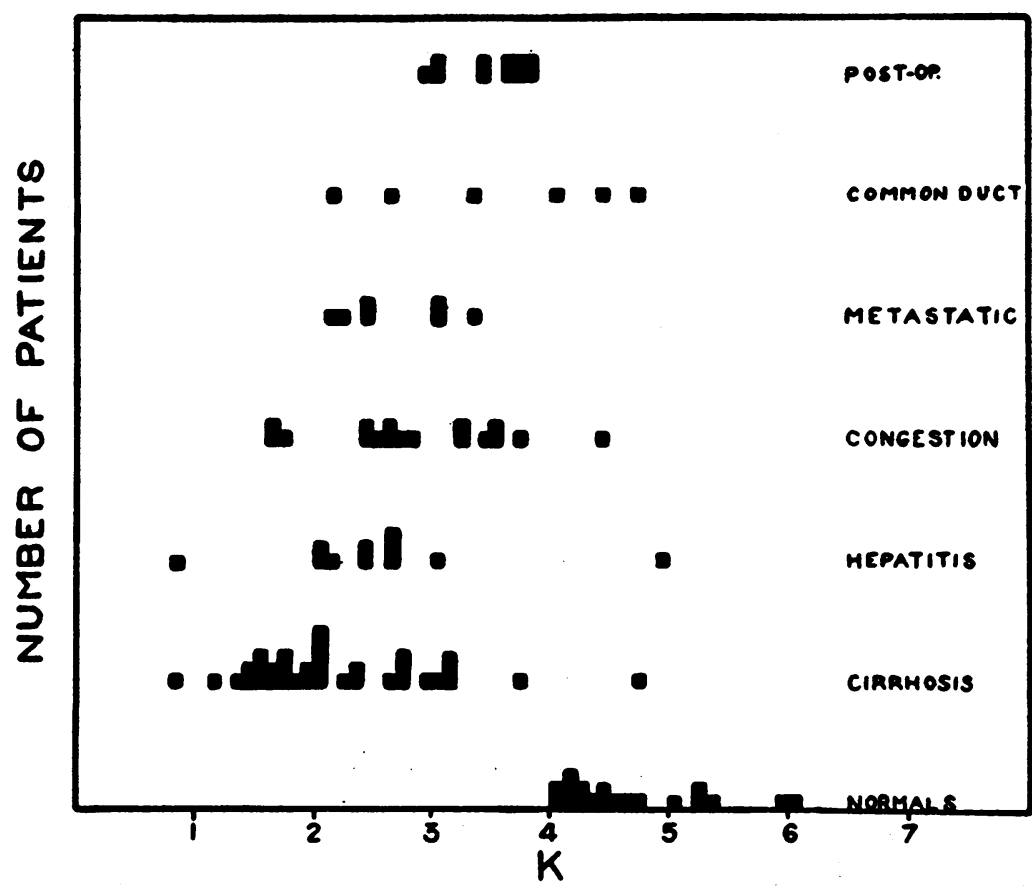

Fig. 5. Rate of Decline of Serum Cinnamate (K) as Per Cent Per Minute Change in Serum Concentration Following Intravenous Injection of Sodium Cinnamate in 105 Tests in Normals and Various Hepatic and Other Disease States 
TABLE I

Fasting serum glucuronic acid level mg./100 ml.*

\begin{tabular}{|c|c|c|c|c|c|c|c|}
\hline \multirow{2}{*}{ Diagnosis } & \multicolumn{6}{|c|}{ Weeks in hospital } & \multirow{2}{*}{ Comment } \\
\hline & 1 & 2 & 3 & 4 & 5 & 6 & \\
\hline $\begin{array}{l}\text { 1. Hepatitis } \\
\text { 2. Hepatitis } \\
\text { 3. Hepatitis } \\
\text { 4. Hepatitis } \\
\text { 5. Cirrhosis } \\
\text { 6. Cirrhosis } \\
\text { 7. Cirrhosis } \\
\text { 8. Cirrhosis } \\
\text { 9. Cirrhosis } \\
\text { 10. Cirrhosis }\end{array}$ & $\begin{array}{l}4.7 \\
7.3 \\
4.7 \\
7.7 \\
6.3 \\
6.0 \\
4.9 \\
4.3 \\
4.3 \\
5.6\end{array}$ & $\begin{array}{l}2.9 \\
3.6 \\
3.8 \\
5.0 \\
6.4 \\
3.6 \\
\frac{5}{5.5}\end{array}$ & $\begin{array}{l}3.5 \\
4.1 \\
3.5 \\
4.3 \\
8.4 \\
3.6 \\
3.6 \\
6.1\end{array}$ & $\begin{array}{c}3.2 \\
3.1 \\
3.5 \\
4.0 \\
4.9 \\
- \\
5.2\end{array}$ & $\begin{array}{l}3.5 \\
3.7 \\
5.9\end{array}$ & 3.9 & $\begin{array}{l}\text { Recovery } \\
\text { Recovery } \\
\text { Recovery } \\
\text { Recovery } \\
\text { Improved } \\
\text { Delayed improvement } \\
\text { Improved } \\
\text { Unchanged } \\
\text { Slight improvement } \\
\text { Died in 5th week }\end{array}$ \\
\hline
\end{tabular}

* Uncorrected for glucose (see text).

tory operation, autopsy findings, or liver biopsy were utilized in approximately one-third of the patients in arriving at a definitive diagnosis.

In two patients with multiple myeloma, $\mathrm{K}$ values over 6.0 per cent per minute were observed (7.9 and 8.0). The latter, in addition, had 5 minute cinnamate levels of only 1.2 and $1.4 \mathrm{mg}$. per 100 ml., which was considerably lower than any other subject tested and indicative of an accelerated removal of cinnamate. A return of the 5 minute and $K$ values to normal was observed in one patient while under treatment with urethane and cortisone. A third patient with myeloma had a low 5 minute level (1.7) and low $K$ value (3.4) both of which rose to normal (2.0,4.3, respectively) under urethane therapy. A fourth patient in an early clinical stage of this disease without roentgen evidence of bony destruction had normal findings.

After intravenous cinnamate there was no marked change in the inorganic phosphorus or glucuronic acid levels as compared to the control fasting state. However, an elevation above the normal was seen in the fasting control glucuronic acid value in the patients with active liver damage, the glucose level being unchanged. Thus, with the method given we found that in the normal subject glucuronic acid values (uncorrected for glu- cose) were in the range 2.3 to $4.0 \mathrm{mg}$. per $100 \mathrm{ml}$. (42 determinations with the mean of 3.2 and S.D. of 0.5 ), while a group of 75 liver patients in various stages of hepatitis, cirrhosis, metastasis and congestion had a mean level of $4.8 \mathrm{mg}$. per $100 \mathrm{ml}$. with S.D. of 1.4 (Figure 6). This is a statistically significant difference. In this regard it is of interest that in ten unselected hepatitis or cirrhosis patients in whom repeat determinations were made, elevated values returned to normal in the patients undergoing remission and were unchanged in the unimproved (Table I). With the glucuronic acid method of Fishman, Smith, Thompson, Bonner, Kasdon, and Homburger, a correction for glucose content was not found significant in the normal or liver damage group, but of importance in the diabetic where the deviation due to glucose may be large (10).

\section{DISCUSSION}

A summary of recorded observations of metabolic pathways in the fate of cinnamic acid after ingestion by human subjects is indicated in Figure 7. These data are based on measurements of conjugation products excreted in the urine. In the dosage given the normal pathway (counterclockwise in Figure 7) is largely by beta oxidation to benzoic acid and conjugation of the latter with glycine to form hippuric acid. In liver damage there is diminished oxidation to benzoate and diminished glycine production and conjugation, with greater use of the glucuronic acid conjugation system (clockwise in Figure 7).

With the development by the authors of a method of measurement of blood cinnamate level, a further trial of cinnamic acid as a liver test substance was performed. In the liver damage group, the orally administered test demonstrated again the impaired oxidation of cinnamate to benzoate by the elevation of serum cinnamate levels and

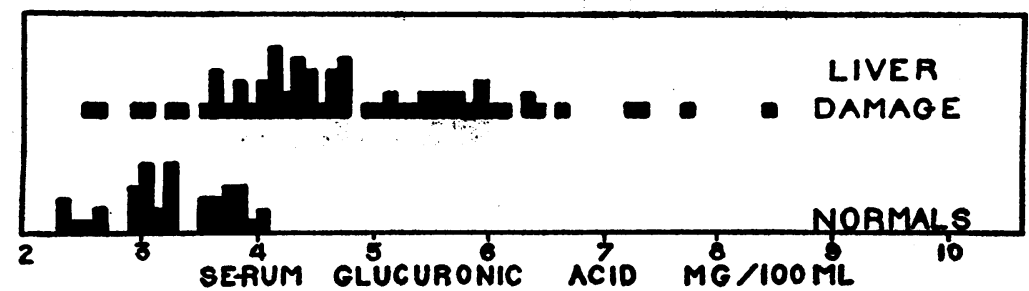

Fig. 6. Range of Glucuronic Acid Values in the Fasting State in Normal Subjects and in Patients with Liver Disease 


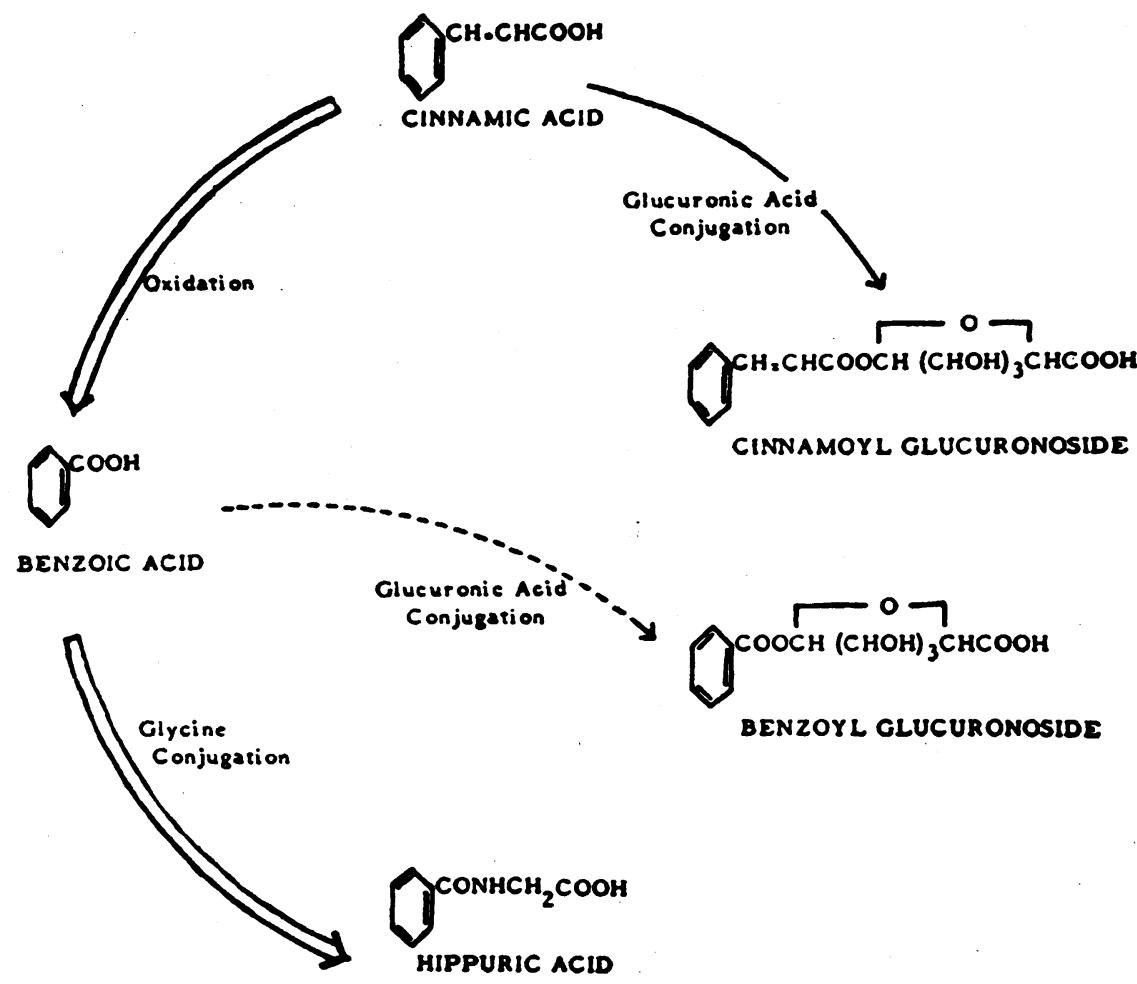

Fig. 7. Metabolic Pathways of Cinnamic Acid

The normal pathway is largely counterclockwise. In liver damage with impairment of oxidation of cinnamate to benzoate and glycine conjugation to hippurate, there is increased demand on the glucuronic acid conjugation system (clockwise).

concomitant decreased excretion of hippuric acid in the urine. Since the glucuronic acid level was unchanged over the control value, it can be assumed that the excess of unoxidized cinnamate was circulating as a sodium salt rather than as a conjugated compound. No significant change was noted in the glucose and phosphorus levels in the patients studied. The latter indicated that the intact human being given the dosage employed in this study reacts differently from isolated rat and guinea pig kidney and liver slices as studied by Weinbach, Lowe, Frisell, and Hellerman (11). They noted that the presence of cinnamate will presumably increase the rate of utilization of glucose as seen from lactate accumulation which is paralleled by increased glucose removal.

The rate of decline of serum cinnamate concentration following intravenous administration appears to offer a suitable index of the oxidative function of the liver. From the distribution of results obtained in various disease states, and from serial determinations made in patients with liver damage with correlation to the clinical status, it is apparent that there is a direct relationship between the functional adequacy of the liver and the rate of removal of cinnamate. The clinical material clearly points to the liver as the principal site of this metabolic activity.

Unlike the sulphobromphthalein sodium retention test, the presence of jaundice interferes neither with the metabolic pathway nor the method of determination of cinnamate. Low rates of serum cinnamate removal were seen in hepatitis, cirrhosis and congestive hepatomegaly in direct relationship with the clinical status of the patient. With improvement in hepatitis the values returned to the normal range, but in the cirrhotics the improvement was not as marked. Normal or near normal values were found in the latent or well compensated cirrhosis patients who were under hospital surveillance for other reasons. Since a close correlation was found between the rate of cinnamate decline in the serum and the severity of the liver injury, the results of this test may have a prog- 
nostic importance. No definite statement can as yet be made as to the significance of a particular range of values with this test compared to routine liver function studies until a much larger homogeneous series of patients are studied.

In two patients with multiple myeloma, the rate of removal of cinnamate was increased to almost twice normal. It follows that this may be due, in part, to the metabolic activity of the myeloma cells. In one patient in whom the latter was suppressed by urethane and cortisone, $K$ values dropped to normal.

A mild elevation in the fasting glucuronic acid levels in a proportion of patients with liver disease was noted, along with a rapid return to normal early in the course of improvement. If further observations bear out this finding, it may be a prognostic guide with these patients. Simultaneous glucose determinations were in the normal range. While large doses of drugs may cause glucuronic acid elevation, most of the liver patients received only diet and vitamins and had the above mentioned changes with continuation of the same therapy. These data may be interpreted as indicating the greater use of glucuronide conjugation mechanism in the acute phase of liver injury, possibly for the removal of endogenous metabolites that are not handled through their normal pathways. In that respect, it may parallel the increased glucuronide conjugation with benzoic or cinnamic acids as test materials when the primary methods of removal, glycine conjugation and oxidation, respectively, are impaired.

\section{SUMMARY AND CONCLUSIONS}

1. A method for the determination of serum cinnamate by measurement of a cadmium hydroxide filtrate in the ultraviolet at $270 \mathrm{~m} \mu$ is presented.

2. Cinnamic acid administered orally in dosage of 0.6 gram per $30 \mathrm{lb}$. to normal subjects gave average serum cinnamic acid levels of less than $3.5 \mathrm{mg}$. per $100 \mathrm{ml}$. with conversion of 67 to 94 per cent hippuric acid in a six hour period. In patients with hepatocellular disease the serum cinnamic acid levels were elevated, ranging 4.2 to $13.8 \mathrm{mg}$. per $100 \mathrm{ml}$. with decreased conversion to hippuric acid and no significant changes in serum glucuronides, glucose, or inorganic phosphorus.

3. An important metabolic derangement in hepatic disorders, that of diminished oxidative ca- pacity, may be conveniently measured with sodium cinnamate as the test substance. The rate of decline of serum cinnamate after intravenous in.jection with the dosage of $5 \mathrm{mg}$. per $\mathrm{kg}$. can serve as an index of hepatic oxidative ability; the normal value is 4.0 to 6.0 per cent per minute. In hepatocellular damage the rate is decreased to as low as 0.8 per cent per minute and as seen from serial determinations is in direct relation to the clinical state of the patient. In 125 tests performed, minor side effects such as flushing and transient abdominal pain were occasionally present. The presence of jaundice interferes neither with the method of analysis nor the metabolic pathway. The indications are that the results of this test may have clinical usefulness in the evaluation of the extent of liver injury in conjunction with other laboratory aids.

4. Increased rates of removal of cinnamate from serum may occur in multiple myeloma as observed in two patients.

5. Patients with liver damage had a significant elevation of the concentration of serum glucuronic acid in the fasting state as compared with normal controls. With improvement in the clinical course of the liver disturbance there was a return of fasting glucuronic acid level to the normal.

\section{REFERENCES}

1. Snapper, I., and Saltzman, A., Excretion of glucuronates after ingestion of benzoic or cinnamic acid as a test of liver function. Trans. 7th Conf. Liver Injury, 1948, 77.

2. Snapper, I., and Saltzman, A., Hippuric acid, cinnamoylglucuronic acid and benzoylglucuronic acid in the urine of normal individuals and in patients with hepatic dysfunction after ingestion of sodium cinnamate. Arch. Biochem., 1949, 24, 1.

3. Snapper, I., Personal communication.

4. Snapper, I., Yü, T. F., and Chiang, Y. T., Cinnamic acid metabolism in man. Proc. Soc. Exper. Biol. \& Med., 1940, 44, 30.

5. Sharnoff, J. G., Budnick, M., and Jakab, G., Evaluation of benzoyl glucuronate excretion test (Snapper) for liver dysfunction. Am. J. Clin. Path., 1951, 21, 234.

6. Benedict, S. R., The analysis of whole blood. II. The determination of sugar and of saccharoids (nonfermentable copper-reducing substances). J. Biol. Chem., 1931, 92, 141.

7. Benedict, S. R., and Theis, R. C., A modification of the molybdic method for the determination of inorganic phosphorus in serum. J. Biol. Chem., 1924, 61, 63. 
8. Fishman, W. H., Smith, M., Thompson, D. B., Bonner, C. D., Kasdon, S. C., and Homburger, F., Investigation of glucuronic acid metabolism in human subjects. J. Clin. Invest., 1951, 30, 685.

9. Quick, A. J., The clinical application of the hippuric acid and prothrombin tests. Am. J. Clin. Path., 1940, 10, 222.
10. Saltzman, A., Caraway, W. T., and Beck, I., Blood glucuronic acid level in diabetes mellitus. To be published.

11. Weinbach, E. C., Lowe, H. J., Frisell, W. R., and Hellerman, L., Chemical interferences in cellular metabolism. Cinnamate effects. J. Biol. Chem., 1951, 189, 779. 